\title{
VARIAÇÃO SAZONAL DE ALGUMAS CARACTERÍSTICAS NUTRICIONAIS E BIOQUÍMICAS RELACIONADAS COM A PRODUÇÃO DE LÁTEX EM CLONES DE SERINGUEIRA [Hevea brasiliensis (Wild.) Muell. Arg.)], EM LAVRAS-MG
}

\author{
Seasoned climatic variations of some nutritional and \\ biochemical characteristics related to latex production of \\ rubber trees [Hevea brasiliensis (Willd.) Muell. Arg.], in Lavras-MG
}

\author{
Renato Figueiredo Melo ${ }^{1}$, Luiz Edson Mota de Oliveira ${ }^{2}$, Alessandro Carlos Mesquita ${ }^{3}$, Nelson Delú Filho ${ }^{4}$
}

\begin{abstract}
RESUMO
Objetivou-se com este trabalho avaliar os efeitos das variações climáticas sazonais sobre a produção de látex, a partir de parâmetros relacionados ao fluxo e regeneração de látex e da caracterização bioquímica dos tecidos fonte e dreno, com base nas atividades das enzimas invertase neutra e sintase da sacarose (SuSy). Foram usados folíolos centrais de folhas completamente expandidas de clones de seringueira (RRIM 600, FX 2261 e GT 1) nos meses de dezembro de 2001 e julho de 2002, plantados no Setor de Fisiologia Vegetal da Universidade Federal de Lavras (UFLA). Os dados de produção foram obtidos nos respectivos meses, por meio de sangrias no sistema S 1/2 (D2/D3), além da utilização de borracha seca em estufa para análises minerais. Pelos dados de produção, verificou-se uma superioridade do clone RRIM 600 sobre os demais e um comportamento semelhante entre os outros clones, apresentando valores superiores no mês de dezembro. Para as características bioquímicas avaliadas, as atividades de ambas as enzimas foram superiores no mês de dezembro em todos os clones, sendo mais representativas nos folíolos do clone RRIM 600. Todos os clones apresentaram valores superiores de açúcares redutores e açúcares solúveis totais em dezembro. Os teores de aminoácidos no clone RRIM 600 foram estatisticamente superiores em julho, ao passo que para os demais clones, esses não diferiram. Os teores de proteínas totais foram superiores no mês de dezembro nos clones RRIM 600 e GT 1, sendo no mês de julho para o clone FX 2261. As análises minerais ( $\mathrm{N}, \mathrm{Pi}, \mathrm{Ca}$ e $\mathrm{Mg}$ ) da borracha seca demonstraram valores inferiores no mês de julho para todas as características avaliadas. O clone GT 1 apresentou maiores valores de nitrogênio total, e os teores de Pi, Ca e Mg foram superiores na borracha seca do clone FX 2261.
\end{abstract}

Termos para indexação: Seringueira, látex, invertase, sintase da sacarose.

\begin{abstract}
The objective of this work was to evaluate the effects of seasoned climatic variations on latex production, from parameters related to flux and regeneration of latex and biochemical characterization of source and sink tissues, based on the activities of neutral invertase and sucrose synthase (SuSy). Central leaflet of mature leaves of rubber plant clones (RRIM 600, FX 2261 and GT 1) collected in December 2001 and July 2002, from plants cultivated at the Federal University of Lavras (UFLA) Plant Physiology Section were used. Production data were obtained from the same months, using the S1/2 (D2/D3) tapping system, as well as stove-dried rubber for mineral analyses. The results of production demonstrated a superiority of the RRIM 600 clone, and a similar behavior of the other clones, presenting highest values in December. Both enzyme activities were supain in December in all clones, and higher in baflets of the at RRIM 600 clone. All clones presented superior values of total reducing and soluble sugars in December. Aminoacid levels of the RRIM 600 clone were statiscally superior in july and no difference was found for the other clones. Total protein concentrations were higher in December in the clones RRIM 600 and GT 1, and July for the clones FX 2261. Dried rubber mineral analyses (N, $\mathrm{Pi}, \mathrm{Ca}$ and $\mathrm{Mg}$ ) demonstrated reduced values in July for all evaluated characteristics. The GT 1 clone presented higher values of total nitrogen and the levels of Pi, Ca, and Mg were superior at the drie rubber of Fx 2261 clone.
\end{abstract}

Index terms: Rubber plant, latex, invertase, sucrose synthase.

(Recebido para publicação em 8 de agosto de 2003 e aprovado em 5 de novembro de 2004)

\footnotetext{
1. Bolsista de iniciação cientifica CNPq/UFLA - Universidade Federal de Lavras - Caixa Postal 3037 - 37200-000 - Lavras, MG.

2. Professor Titular do Setor de Fisiologia Vegetal da UFLA.

3. Pesquisador PD/CNPq - UFLA.

4. Professor da UNINCOR, Três Corações, MG.
} 


\section{INTRODUÇÃO}

Tradicionalmente, a seringueira tem sido cultivada na região equatorial entre as latitudes de $10^{\circ} \mathrm{S}$ a $10^{\circ} \mathrm{N}$, com maior produção entre $6^{0} \mathrm{~N}$ e $6^{0} \mathrm{~S}$ (PUSHPARAJAH, 1983). Entretanto, em conseqüência das dificuldades de produção no trópico superúmido da América Latina e do aumento da demanda da borracha natural, várias regiões do mundo, fora da zona convencional, iniciaram seu cultivo. No Brasil, segundo Gonçalves et al. (1991), os plantios estão se expandindo entre latitudes de 19 a $23^{0} \mathrm{~S}$, incluindo Espírito Santo, São Paulo, norte do Paraná e Minas Gerais. Em relação a esse último Estado, a heveicultura encontra-se modestamente instalada em uma área pouco superior a 3.000 hectares, tendo como pólos as regiões do Triângulo Mineiro, Zona da Mata, Alto do São Francisco e Rio Doce.

O grande potencial para a ampliação dessa cultura em Minas Gerais encontra-se nas áreas de solo sob cerrado, que abrangem regiões com diferentes condições edafoclimáticas (ORTOLANI, 1985; MATTIELO et al., 1988). A região sul de Minas Gerais pode ser perfeitamente integrada no contexto heveícola, como se pode verificar no trabalho sobre zoneamento ecológico para a seringueira desenvolvido por Rufino (1986). Apesar de essa região apresentar uma estação seca e fria bem definida, a viabilidade do estudo e da implantação da heveicultura está baseada no desempenho promissor de alguns plantios isolados desenvolvidos por pesquisadores e produtores, porém, ainda dependendo de comprovações experimentais, principalmente quanto à capacidade produtiva dessas plantas. Além disso, a heveicultura nessa região pode representar uma alternativa econômica e ecológica na implantação desses ecossistemas agrícolas.

A produção de látex de seringueira é dependente, entre outros fatores, da disponibilidade de carboidratos de reserva, do transporte de sacarose e da sua demanda por outros tecidos drenos da árvore, do estado hídrico da planta, da biossíntese de aminoácidos e proteínas e da estrutura anatômica dos vasos laticíferos, bem como do "status" nutricional da planta (SÁ, 1991). Para atingir uma boa produção, a capacidade fotossintética da planta deve estar num determinado nível, em que os processos metabólicos possam suprir a demanda daqueles compostos.

Além dos fatores edáficos, as mudanças climáticas sazonais que envolvem flutuações na disponibilidade de luz, temperatura e umidade do ar afetam a atividade fotossintética e, conseqüentemente, o metabolismo do carbono e do nitrogênio, devendo ser uma das principais causas das variações na produção do látex ao longo do ano. Alguns pesquisadores têm estudado de forma genérica os efeitos de fatores edafoclimáticos so- bre a produção de látex (CARRETERO, 1984; SAMSUDDIN et al., 1987; DEVAKUMAR et al., 1988; GONÇALVES et al., 1991). Entretanto, estudos mais específicos, procurando identificar a influência dos fatores edáficos e das variações climáticas sobre o metabolismo do carbono e do nitrogênio e suas relações com a produção de látex nos diferentes períodos sazonais, ainda não foram realizados para seringueira.

A diversidade de características dos solos, e especialmente do clima, impõe o desenvolvimento de tecnologias de cultivo e exploração mais apropriadas para essas regiões. Portanto, os estudos, principalmente a nível metabólico, sobre os problemas relacionados às adversidades climáticas que influenciam o cultivo e a produção da seringueira, nessas áreas, merecem maior atenção.

Nesse sentido, os objetivos propostos neste trabalho foram: i) avaliar os efeitos das variações climáticas sazonais na produção de látex, acompanhando os parâmetros relacionados ao fluxo e regeneração de látex; ii) caracterizar bioquimicamente os tecidos fonte e dreno com base nas atividades das enzimas invertase neutra e sintase da sacarose (SuSy).

\section{MATERIAL E MÉTODOS}

Este experimento foi implantado no campus da Universidade Federal de Lavras (UFLA), na área experimental do Setor de Fisiologia Vegetal/Departamento de Biologia. Foram avaliados três clones de seringueira (RRIM 600, FX 2261 e GT 1), plantados em 1986. As avaliações foram analisadas em delineamento inteiramente casualisado com cinco repetições, sendo utilizado o teste de Tukey a 5\% de probabilidade, para comparação dos contrastes entre médias.

O ambiente foi monitorado por meio de medições de precipitação, temperatura do ar e umidade relativa obtidas na Estação Climatológica da UFLA, situada a uma latitude de $21^{0} 14^{\prime}$ 'S, longitude de $45^{\circ} 00^{\prime} \mathrm{W}$ e altitude de 910 $\mathrm{m}$, localizada a cerca de $300 \mathrm{~m}$ da área experimental. Os valores correspondem às observações obtidas nos dias que antecederam as sangrias, que foram realizadas duas vezes por semana, totalizando 13 avaliações ao final de cada mês.

As avaliações representativas do período quente e chuvoso foram realizadas em dezembro de 2001, enquanto as representativas do período frio e seco foram obtidas no mês de julho de 2002. As produções de látex foram obtidas por meio de sangrias no sistema $S \frac{1}{1} 2\left(D_{2} / D_{3}\right)$, sem a utilização de estimulante. $O$ látex de cada sangria foi submetido à secagem em estufa de circulação mecânica com $70^{\circ} \mathrm{C}$, até atingir peso constante. 
MELO, R. F. et al.

Em cada época avaliada, foram quantificados os teores de açúcares redutores (AR), açúcares solúveis totais (AST), aminoácidos (AAs) e proteínas totais, utilizando metodologias que foram descritas por Yemm e Wills (1954), Yemm e Cocking (1955), Muller (1959) e Bradford (1976), respectivamente, além das atividades das enzimas invertase neutra (IN) e sintase da sacarose (SuSy), que foram quantificadas segundo metodologia descrita por Oliveira (1985) e Delú-Filho (1994), respectivamente. As análises bioquímicas foram realizadas utilizando-se o folíolo central de folhas completamente expandidas (estádio D).

Nos períodos avaliados, amostras de borracha seca foram retiradas para quantificação das seguintes características relacionadas ao fluxo e regeneração do látex: teores de nitrogênio total, magnésio $\left(\mathrm{Mg}^{+2}\right)$, cálcio $\left(\mathrm{Ca}^{+2}\right)$ e fósforo inorgânico $(\mathrm{Pi})$, em que:

- Teores de magnésio, cálcio e fósforo: as amostras previamente desidratadas foram submetidas à digestão nitroperclórica, e a determinação dos íons foi feita por meio de absorção atômica (Mg, Ca e P). Essas análises foram realizadas no Laboratório de Análise Foliar do Departamento de Química da UFLA.

- Nitrogênio total: as amostras previamente desidratadas foram submetidas à digestão sulfúrica (método Kjeldahl), e posteriormente destiladas. Em seguida, foram quantificadas por titulação com $\mathrm{HCl}$ 0,07143 N. Essas análises foram realizadas no Laboratório de Bioquímica e Metabolismo de Plantas do Setor de Fisiologia Vegetal da UFLA.

\section{RESULTADOS E DISCUSSÃO}

As épocas de avaliação (dezembro e julho) apresentaram valores de temperatura, precipitação e umidade relativa do ar típicos das condições climáticas normalmente verificadas em suas respectivas estações. $\mathrm{Na}$ Tabela 1, observa-se que a temperaturas média dos dias que antecederam as sangrias no mês de dezembro de 2001 foi de $21,84^{\circ} \mathrm{C}$, enquanto em julho de 2002 , a temperatura média foi de $14,13^{\circ} \mathrm{C}$.

TABELA 1 - Valores de temperatura, precipitação e umidade relativa referentes aos dias que antecederam as sangrias nos meses de dezembro de 2001 e julho de 2002.

\begin{tabular}{cccccc}
\hline \multicolumn{2}{c}{ Temperatura $\left({ }^{\mathbf{0}} \mathbf{C}\right)$} & \multicolumn{2}{c}{ Precipitação (mm) } & \multicolumn{2}{c}{ Umidade Relativa (\%) } \\
\hline Dezembro & Julho & Dezembro & Julho & Dezembro & Julho \\
\hline 22,1 & 14,5 & 0,0 & 0,0 & 68,0 & 33,2 \\
22,0 & 14,2 & 16,0 & 0,0 & 82,0 & 30,0 \\
20,5 & 16,2 & 0,0 & 0,0 & 63,0 & 32,4 \\
23,9 & 15 & 3,8 & 0 & 81,0 & 35,4 \\
22,0 & 14,4 & 1,6 & 10,5 & 78,0 & 65,4 \\
21,2 & 13,4 & 11,4 & 5,2 & 57,0 & 62,2 \\
24,2 & 14,5 & 10,8 & 0 & 95,0 & 52,3 \\
20,3 & 13,2 & 0,0 & 0,0 & 58,0 & 49,2 \\
23,4 & 13,7 & 0,0 & 0,0 & 68,0 & 42,3 \\
23,8 & 12,5 & 4,4 & 0 & 93,0 & 42,2 \\
20,3 & 14,1 & 0,0 & 0,0 & 82,0 & 38,5 \\
22,3 & 13,6 & 8,8 & 4,2 & 93,0 & 49,5 \\
17,9 & 14,4 & 18,7 & 0 & 96,0 & 46,5 \\
\hline Soma = 283,9 & 183,7 & 75,5 & 19,9 & 1014 & 579,1 \\
\hline Média = 21,84 & 14,13 & 5,8 & 1,53 & 78 & 44,5 \\
\hline
\end{tabular}

Fonte: Estação climatológica da UFLA. 
Quando se observa o comportamento da precipitação, verifica-se pelos dados que as chuvas foram bem distribuídas no mês de dezembro, propiciando boa disponibilidade de água no solo $(75,5 \mathrm{~mm})$. Em julho, as chuvas foram escassas, com um valor acumulado de precipitação de 19,9 mm.

Em relação às umidades relativas de dezembro, essas variaram entre 57 e 96\%, com valor médio de $78 \%$, resultado das precipitações ocorridas no período; no mês de julho, os valores oscilaram entre 30 e 65\%, resultando em um valor médio de 44,5\%.

Oliveira (1999) e Lima et al. (2002), avaliando o efeito das variações edafoclimáticas na produção do clone RRIM 600, observaram que o mês de agosto foi caracterizado por um período mais seco, em função da falta de chuvas, mantendo uma umidade relativa média inferior à de dezembro. Esse mesmo comportamento foi observado durante a condução deste trabalho, porém, no mês de julho.

Observa-se na Figura 1 que o clone RRIM 600 apresentou sua maior produção (média de 95 g borracha seca/sangria) em dezembro, ao passo que em julho a produção foi inferior (59 g borracha seca/ sangria). Um comportamento produtivo proporcionalmente semelhante a esse foi obtido por Oliveira (1999) e Lima et al. (2002). Esses autores registraram, em relação ao mesmo clone, produções médias em torno de 5,0 e 8,5 g de borracha seca/sangria em agosto, e de 20,0 e $17,5 \mathrm{~g}$ de borracha seca/sangria em dezembro, respectivamente. Deve-se ressaltar que esses valores referem-se ao primeiro ano de sangria das árvores estudadas.

O comportamento produtivo do clone GT 1 foi igualmente influenciado pelas variações climáticas, embora com produção inferior, em torno de 54 e 26 g de borracha seca/sangria nos meses de dezembro e julho, respectivamente. A variação climática das estações não alterou o comportamento produtivo do clone
Fx 2261, cuja produção obtida foi a menor entre os clones (8,0 g de borracha seca/sangria) nos dois períodos avaliados.

Segundo Lima et al. (2002), as características climáticas de dezembro, especialmente temperaturas médias mais elevadas e maior ocorrência de chuvas, constituem-se em fator que favorece a maior disponibilidade de açúcares prontamente assimiláveis (redutores) nos tecidos laticíferos, o que pode justificar a maior produção de borracha.

Os teores de nitrogênio encontrados na borracha seca dos clones RRIM 600 e GT 1 (Figura 2) em dezembro foram inferiores aos de julho. No clone Fx 2261 , verificou-se um resultado inverso.

Os teores de fósforo inorgânico da borracha seca (Figura 3) em dezembro foram superiores aos registrados em julho, em todos os clones avaliados. Os maiores teores foram os do clone Fx 2261.

Na Figura 4, verifica-se que não houve diferenças significativas nos teores de cálcio obtidos em cada clone, quando se comparam as duas épocas avaliadas.

Quanto ao magnésio (Figura 5), todos os clones apresentaram os teores na borracha seca em dezembro superiores aos de julho. O mês de julho, além de apresentar valores inferiores, demonstrou uma superioridade do clone GT 1 em relação aos demais.

Observa-se que os teores de P (Figura 3) e Mg (Figura 5) sofreram redução nos seus níveis em julho, período em que a produção de borracha diminui. Em linhas gerais, as relações desses parâmetros com os mecanismos de produção foram descritas por Jacob e Serres (1988) e Jacob e Prevot (1989), os quais afirmam que o fósforo inorgânico representa entre $60 \%$ e $80 \%$ do fósforo do látex, o que reflete a intensidade das trocas energéticas e, principalmente, a utilização do isopentenilpirofosfato na polimerização da borracha.

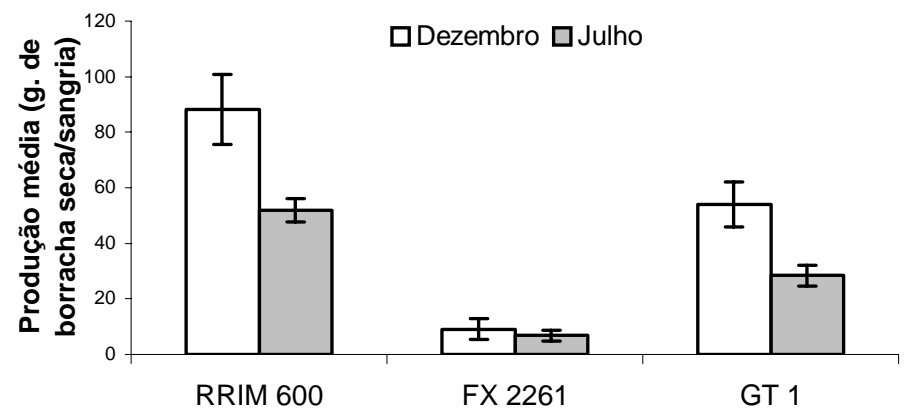

FIGURA 1 - Produção de borracha seca dos clones de seringueira nos meses de dezembro de 2001 e julho de 2002. 


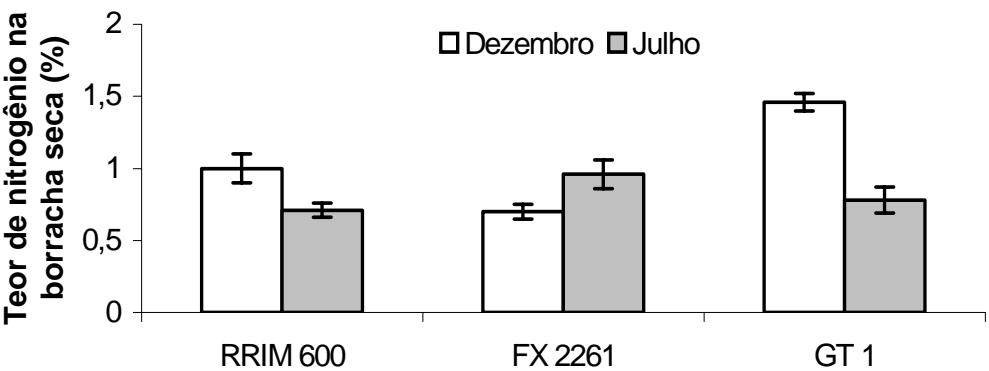

FIGURA 2 - Teores de nitrogênio na borracha seca dos clones nos meses de dezembro de 2001 e julho de 2002.

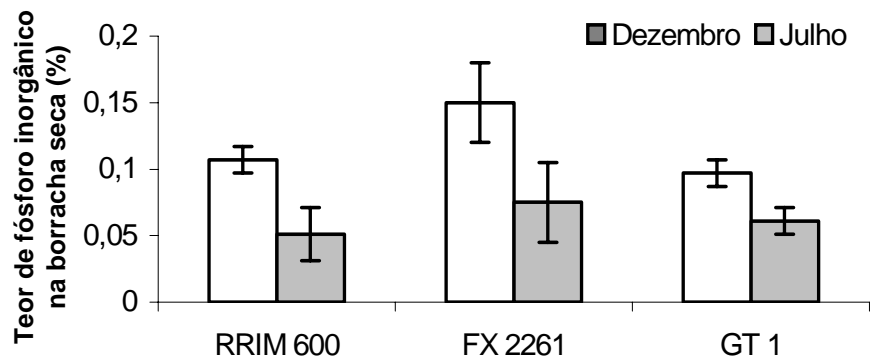

FIGURA 3 - Teores de fósforo inorgânico na borracha seca dos clones nos meses de dezembro de 2001 e julho de 2002.

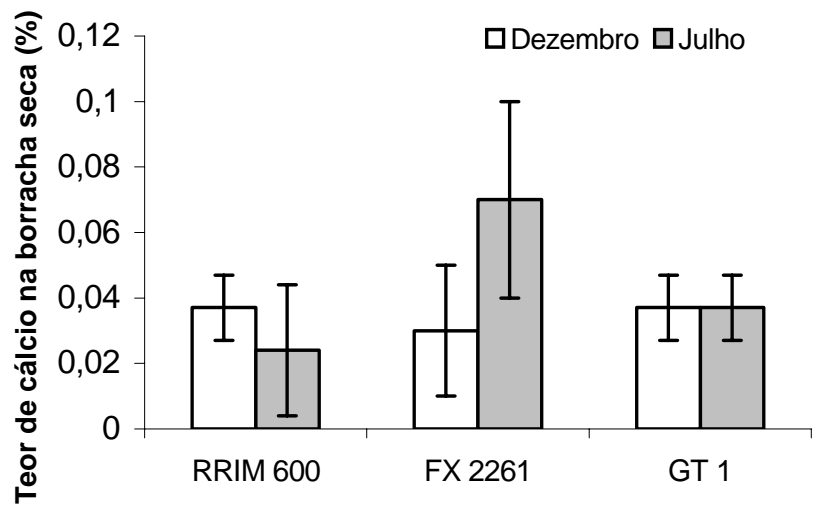

FIGURA 4 - Teores de cálcio na borracha seca dos clones nos meses de dezembro de 2001 e julho de 2002.

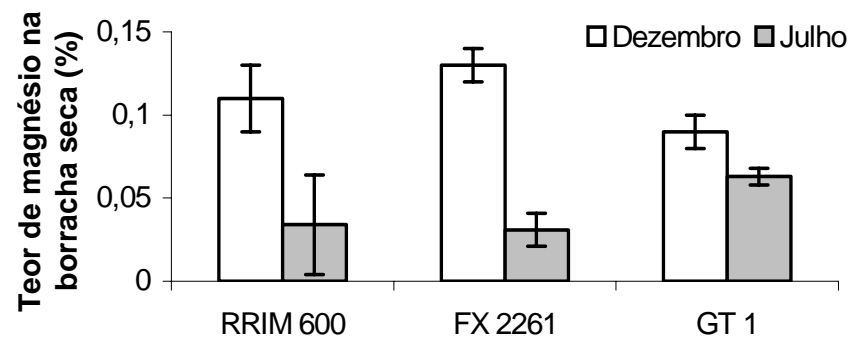

FIGURA 5 - Teores de magnésio na borracha seca dos clones nos meses de dezembro de 2001 e julho de 2002.

Ciênc. agrotec., Lavras, v. 28, n. 6, p. 1326-1335, nov./dez., 2004 
Segundo Moraes e Moraes (1995), o significado de cada nutriente (P, Ca e Mg) somente pode ser avaliado em confronto com os valores de outros parâmetros associados e também com a produção. O teor elevado de Pi indica um metabolismo isoprênico ativo se a produção for alta, o que corresponde à utilização de sacarose não limitada pelo $\mathrm{pH}$ e à ausência de restrição apreciável do escoamento. Entretanto, plantas com secamento de painel podem ter Pi alto, porque esse não é reutilizado na síntese de ATP e de isopentenilpirofosfato e, nesse caso, o teor de sacarose pode também ser alto. Em plantas normais, um Pi baixo indica baixo metabolismo isoprênico, associado a produções mais baixas. Os mesmos autores verificaram que o magnésio em concentrações altas no citossol atua como desestabilizante do látex, interferindo negativamente no escoamento. Por outro lado, é ativador de enzimas, como ATPases em geral, fosfoenolpiruvato carboxilase e fosfofrutoquinase, podendo ser limitante em concentrações muito baixas.

De acordo com a Figura 6, os teores de aminoácidos foram maiores em julho nos folíolos do clone de RRIM 600, ao passo que os clones FX 2261 e GT 1 não apresentaram diferenças entre si nas quantidades de aminoácidos registradas nas duas épocas. Segundo Oliveira (1999), o aumento do teor de aminoácidos totais em plantas sob baixa disponibilidade de água também foi observado no clone RRIM 600.
Correa et al. (1986/87), trabalhando com o clone IAN 873, observaram um aumento na concentração de prolina, que parece ser o aminoácido com maior contribuição para essa condição climática.

Na Figura 7, observa-se que o clone FX 2261 apresentou os maiores teores de proteínas nos folíolos coletados no mês de julho, enquanto os clones RRIM 600 e GT 1 apresentaram os maiores teores no mês de dezembro.

Segundo Hanson e Hitz (1982), a diminuição no teor de proteínas solúveis totais é comum em tecidos em crescimento, em que há rápida inibição de síntese protéica, em razão da baixa disponibilidade de água; o contrário ocorre em tecidos fisiologicamente maduros.

Os teores de açúcares solúveis totais foram maiores nos clones RRIM 600 e GT 1 no mês de dezembro, ao passo que nos folíolos do clone FX 2261 não houve diferença entre as duas épocas (Figura 8).

Na Figura 9, observa-se que os teores de açúcares redutores foram superiores no mês de dezembro, nos três clones avaliados.

Tanto para os teores de AR (Figura 9) quanto para AST (Figura 8), os resultados assemelham-se aos obtidos por Oliveira (1999), cujo trabalho foi conduzido com os clones RRIM 600 e GT 1.

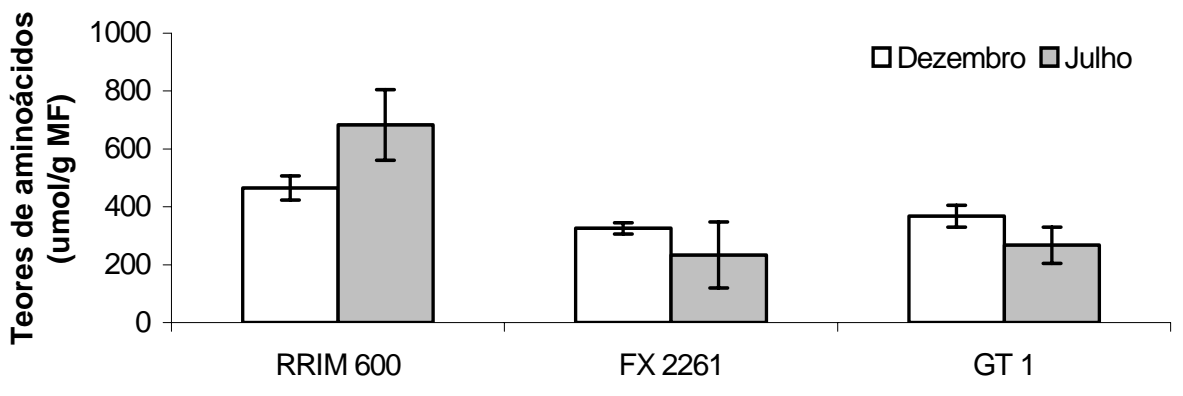

FIGURA 6 - Teores de aminoácidos totais (Aas) em lâminas foliares de clones de seringueira nos meses de dezembro de 2001 e julho de 2002.

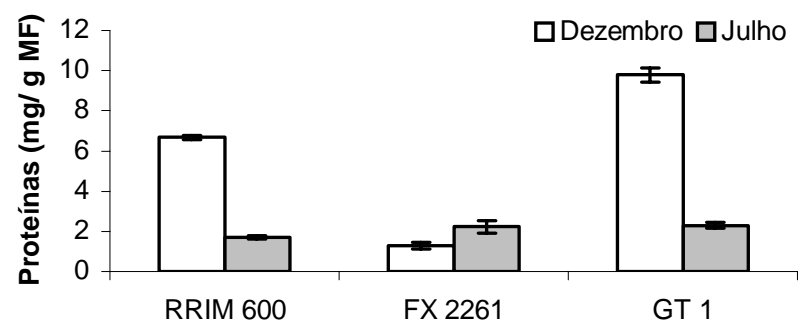

FIGURA 7 - Teores de proteínas totais em lâminas foliares de clones de seringueira nos meses de dezembro de 2001 e julho de 2002. 


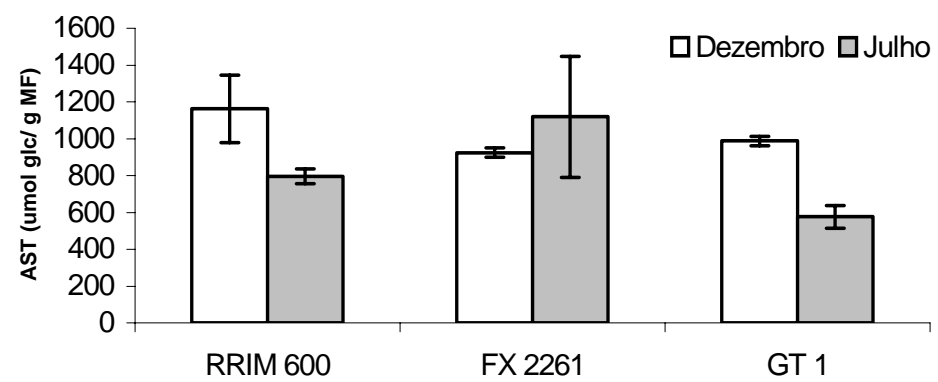

FIGURA 8 - Teores de açúcares solúveis totais (AST) em lâminas foliares de clones de seringueira nos meses de dezembro de 2001 e julho de 2002.

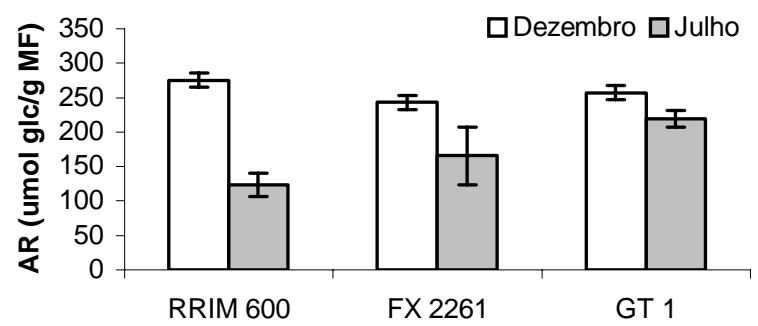

FIGURA 9 - Teores de açúcares redutores (AR) em lâminas foliares de clones de seringueira nos meses de dezembro de 2001 e julho de 2002.

Segundo Lima et al. (2002), a diferença entre os conteúdos de AST e AR representa a disponibilidade total de açúcares com função de transporte, principalmente a sacarose. Assim, as maiores diferenças entre esses açúcares indicam maiores quantidades de sacarose. Com base nisso, observa-se nas Figuras 8 e 9 que a quantidade de sacarose disponível nas folhas foi bem inferior na avaliação de julho nos clones RRIM 600 e GT 1, significando que o carboidrato utilizado como substrato para a biossíntese do látex não foi um fator limitante da produção em dezembro (Figura 1), dependendo apenas da sua translocação até os vasos laticíferos e da sua hidrólise pela atividade da invertase, para aí, sim, iniciar o processo de biossíntese do látex.

A biossíntese do látex envolve uma seqüência de reações que pode, em termos simplificados, ser dividida em duas fases: 1) catabolismo de glicídeos, por meio da glicólise, transformando sacarose em acetato; 2) síntese do isopentenil difosfato, unidade base da policondensação em borracha (PUJADE-REUNARD et al., 1994). Analisando a primeira fase da biossíntese, observa-se que o suprimento de sacarose nos tubos laticíferos e a velocidade de sua utilização, dada pela hidrólise catalisada pela invertase, são fatores limitantes no metabolismo e na produção de borracha (TUPY, 1985; CONDURÚ NETO, 1986; CASTRO, 1990).

Na Figura 10, observa-se que a atividade da invertase neutra foi maior no mês de dezembro, em todos os clones. Essa maior atividade da enzima vem comprovar uma maior translocação e acúmulo de carboidratos nessa época do ano, o que se reflete na maior produção de látex. Esses resultados também mostram que a atividade da invertase neutra é sensível a baixas temperaturas, como demonstrado na Tabela 1 para o mês de julho. Oliveira (1999) demonstrou que as temperaturas mínimas observadas no mês de agosto foram bem inferiores àquelas observadas em dezembro e que esse parâmetro climático parece ser bastante influente na produção de látex, uma vez que as invertases mostraram-se bastante sensíveis às baixas temperaturas.

Yeang (1984), acompanhando a variação sazonal da atividade da invertase, verificaram que, nos meses de temperaturas mais baixas, houve uma menor atividade dessa enzima. Esse mesmo comportamento foi observa-

Ciênc. agrotec., Lavras, v. 28, n. 6, p. 1326-1335, nov./dez., 2004 
do nos três clones de seringueira aqui avaliados (Figura 10). Esses mesmos autores citam que o envolvimento da invertase com a produção de látex relaciona-se com o fornecimento de frutose e glicose, que são produtos da hidrólise de sacarose. Esses açúcares são rapidamente metabolizados e sua concentração no látex não reflete, necessariamente, sua importância.

Na Figura 11 observa-se que a atividade da sintase da sacarose (SuSy) também foi superior no mês de dezembro, em todos os clones. Como a invertase, a SuSy mostra-se sensível às baixas temperaturas de julho.

Segundo Oliveira (1999), a principal função da enzima sintase da sacarose em órgãos drenos é a hidrólise da sacarose transportada pelo floema, catalisando o primeiro passo da rota de biossíntese de amido. Contu- do, pode-se observar neste trabalho a presença dessa enzima também atuando na síntese da sacarose em órgãos fontes.

Segundo Isla et al. (1998) e seus colaboradores, em alguns trabalhos apontam-se as invertases como fornecedoras de açúcares simples para atender à necessidade energética das células, enquanto a sintase da sacarose, que também hidrolisa a sacarose, é usada em processos biossintéticos.

Novos estudos devem ser realizados para verificar a influência dos fatores climáticos sobre as atividades enzimáticas da invertase e da sintase da sacarose nos tecidos foliares, como também dos minerais presentes na borracha seca, associando-os à produção de borracha seca, visando a obter um parâmetro confiável de seleção de materiais promissores.

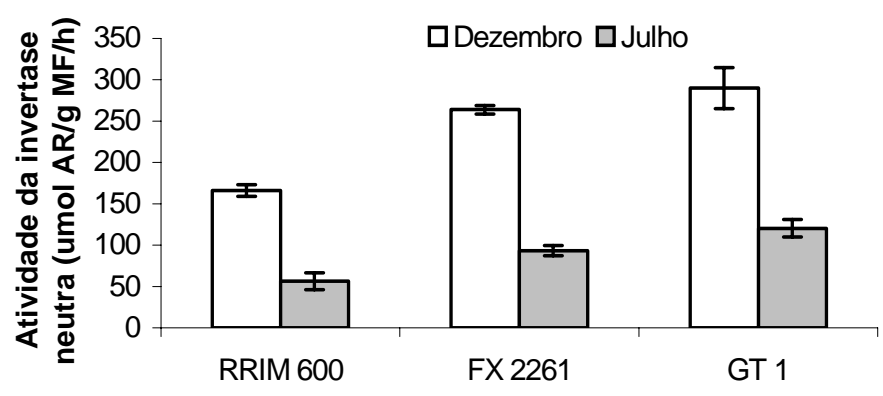

FIGURA 10 - Atividade da invertase neutra em lâminas foliares de clones de seringueira nos meses de dezembro de 2001 e julho de 2002.

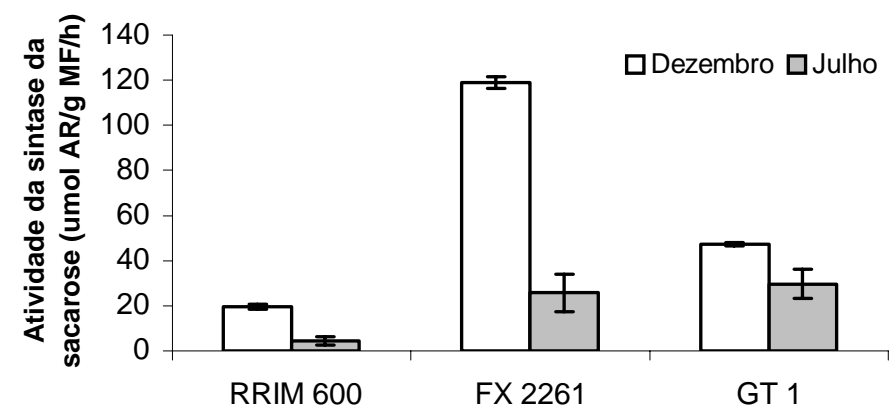

FIGURA 11 - Atividade da sintase da sacarose (SuSy) em lâminas foliares de clones de seringueira nos meses de dezembro de 2001 e julho de 2002. 


\section{CONCLUSÕES}

Os maiores valores de produção de borracha seca foram observados no mês de dezembro e coincidem com o período de maiores ocorrências pluviométricas e temperaturas médias mais elevadas em relação às observadas em julho.

Não houve diferença na produção de borracha seca nos meses avaliados para o clone Fx 2261, que foi inferior aos demais clones.

Os teores de fósforo e magnésio na borracha seca foram superiores em dezembro em todos os clones avaliados.

Em todos os clones, as atividades da invertase neutra e da sintase da sacarose foram maiores no mês de dezembro.

As temperaturas médias observadas em julho foram bem inferiores àquelas demonstradas em dezembro, sendo esse parâmetro climático importante, uma vez que a invertase neutra e a sintase da sacarose mostraram-se bastante sensíveis às baixas temperaturas.

Os teores de açúcares redutores foram maiores no mês de dezembro em todos os clones.

\section{REFERÊNCIAS BIBLIOGRÁFICAS}

BRADFORD, M. M. A rapid and sensitive meted for the quantification of microgram quantities of protein utilizing the principle of protein-dye binding. Analytical Biochemistry, New York, v. 72, p. 248-254, 1976.

CARRETERO, M. V. Efeitos de fatores climáticos e de clones de seringueira (Hevea $\mathrm{sp}$ ) na produção de látex em Pariquera-Açú e Campinas. 1984. 51 f. Tese (Doutorado) - Escola Superior de Agricultura de Luiz de Queiroz, Piracicaba, 1984.

CASTRO, P. R. C. Bases fisiológicas da produção e da estimulação de Hevea brasiliensis. In: BERNARDES, M. S. Sangria da seringueira. Piracicaba: ESALQ, 1990. p. 1-25.

CONDURÚ NETO, J. M. H. Fatores limitantes e parâmetros fisiológicos da produção da seringueira. Belém: Faculdade de Ciências Agrárias do Pará, 1986. 20 p.

CORREA, A. F. F.; RANZANI, G.; FERREIRA, L. G. R. Relações entre o déficit hídrico e alguns processos fisiológicos e bioquímicos em quatro clones de seringueira. Acta Amazônica, Manaus, v. 16/17, p. 3-12, 1986/87.
DELÚ FILHO, N. Efeitos do $\mathbf{N}-\mathbf{N O}_{3}$ sobre o crescimento e atividade das enzimas de assimilação do nitrogênio em plantas jovens de seringueira (Hevea brasiliensis Muell. Arg.). 1994. 87 f. Dissertação (Mestrado) - Universidade Federal de Lavras, Lavras, 1994.

DEVAKUMAR, A. S. et al. Studies on soil-plantatmosphere system in Hevea: II. seasonal effects on water relations and yield. Indian Journal of Natural Rubber Research, New Delhi, v. 1, p. 45-60, 1988.

GONÇALVES, P. de S. et al. Clones de hevea: influência dos fatores ambientais na produção e recomendação para o plantio. Campinas: Instituto Agronômico de Campinas, 1991. 32 p. (Boletim técnico, 138).

HANSON, M. D.; HITZ, W. D. Metabolic responses of mesophytes to plant water deficits. Annual Review of Plant Physiology, Palo Alto, v. 33, p. 163-203, 1982.

ISLA, M. I.; VATTUONE, M. A.; SAMPIETRO, A. R. Hydrolysis of sucrose within isolated vacuoles from Solanum tuberosum L. tubers. Planta, Stuttgart, v. 205, p. 601-605, 1998.

JACOB, J. L.; PREVOT, J. C. Yield limiting factors, latex physiological parameters, latex diagnosis and clonal typology. In: D’AUZAC, J.; JACOB, J. L.; CHRESTIN, H. Physiology of rubber tree latex. Boca Raton: CRC, 1989. p. 345-382.

JACOB, J. L.; SERRES, J. C. Mise au point du diagnostic látex chez I'Hevea. Agritop, Montpellier, v. 12, n. 2, p. 97-115, 1988.

LIMA, D. U. et al. Avaliação sazonal da produção de borracha e da dinâmica de carboidratos solúveis em plantas de seringueira (Hevea brasiliensis Muell. Arg.) cultivadas em Lavras, Minas Gerais. Revista Árvore, Viçosa, v. 26, n. 3, p. 377-383, 2002.

MATTIELlO, J. B.; DI PIETRO, C.; CAMARGO, A. P. Café com leite de Seringueira. Cafeicultura Moderna, [S.1.], ano 1, n. 1, p. 37-37, maio/jun. 1988.

MORAES, V. H.; MORAES, L. A. C. Diagnóstico do látex em sangria precoce de seringueira com copas enxertadas: possibilidades de emprego na seleção precoce de clones de copa e de painel. Agrotópica, Ilhéus, v. 7, n. 3, p. 49-62, 1995. 
MULLER, G. L. Use of dinitrosalicylic acid reagent for determination of reducing sugar. Analytical Biochemistry, New York, v. 31, p. 426-428, 1959.

OLIVEIRA, D. P. Variação sazonal da produção de borracha e da atividade da invertase nos clones RRIM 600 e GT 1 de seringueira (Hevea brasiliensis Muell. Arg.). 1999. Dissertação (Mestrado) - Universidade Federal de Lavras, Lavras, 1999.

OLIVEIRA, L. E. M. Comportamento de plantas de cana-de-açúcar (Saccharum sp) sob condições de deficiência hídrica: alterações da assimilação de nitrato e mobilização de açúcares. 1985. 126 f. Tese (Doutorado) - Universidade de Campinas, Campinas, 1985.

ORTOLANI, A. A. Aptidão climática para a agricultura da seringueira em minas Gerais. Informe Agropecuário, Belo Horizonte, v. 11, n. 121, p. 8-12, 1985.

PUJADE-REUNARD, V. et al. Ethylene-induced increase in glutamine synthetase activity and mRNA levels in Hevea brasiliensis latex cells. Plant Physiology, Washington, v. 105, p. 127-132, 1994.

PUSHPARAJAH, E. Problems and potencials for establishing Hevea under difficult environment conditions. Planter, Kuala Lumpur, v. 59, p. 242251, 1983.

RUFINO, D. T. G. Zoneamento ecológico para o cultivo da seringueira no Estado de Minas Gerais. 1986.
70 f. Tese (Doutorado) - Universidade Federal de Viçosa, Viçosa, 1986.

SÁ, T. D. Avaliação ecofisiológica de seringueira (Hevea brasiliensis Muell.Arg.)submetidas a diferentes intensidades de sangria, em ambientes contrastantes do estado de São Paulo. 1991. 132 f. Tese (Doutorado) - Universidade de Campinas, Campinas, 1991.

SAMSUDDIN, Z.; TAN, H.; YOON, P. K. Correlations studies on photosynthetic rates, girth and yield in Hevea brasiliensis. Journal of Natural Rubber Research, [S.l.], v. 2, p. 46-54, 1987.

TUPY, J. Some aspects of sucrose transport and utilization in latex producing bark of Hevea brasiliensis Muell. Arg. Biologia Plantarum, Copenhagen, v. 34, n. 4, p. 51-64, 1985.

YEANG, H. Y. A preliminary investigation into the relationship between latex invertase and latex vessel plugging in Hevea brasiliensis. Journal of Rubber Research Institute of Malaysia, [S.l.], v. 32, p. 50-62, 1984.

YEMM, E. W.; COCKING, E. C. The determination of amino acid with ninhydrin. Analyst, [S.l.], v. 80, p. 209-213, 1955.

YEMM, E. W.; WILLS, A. J. The estimation of carbohydrates in plant extracts by anthrone. The Biochemical Journal, London, p. 508-514, 1954. 